\title{
Controle de qualidade de bombom funcional acrescido de biomassa de banana-verde e geleia de pitanga
}

\section{Quality control of functional bonbon plus biomass of green banana and pitanga jelly}

Control de calidad de bombón funcional añado de biomasa de plátano verde y jalea de pitanga

Leticia Mendes da $\mathrm{Cruz}^{1}$ Rita de Cássia Avellaneda Guimarães ${ }^{2}$

${ }^{1}$ Discente do curso de Nutrição da Faculdade de Ciências Farmacêuticas, Alimentos e Nutrição, Curso de Nutrição da Universidade Federal de Mato Grosso do Sul (UFMS). E-mail: leticiamendescruz@hotmail.com, Orcid: http://orcid.org/0000-0001-8268-6533

${ }^{2}$ Doutora pelo Programa de Pós-Graduação em Saúde e Desenvolvimento na Região Centro-Oeste pela Universidade Federal de Mato Grosso do Sul (UFMS).

Mestre em Biotecnologia pela Universidade Católica Dom Bosco (UCDB) com sanduíche na Universidade Católica de Brasília (UCB) e bolsa CAPES. Graduada em Nutrição pela UCDB. Professora Adjunta Nível III do curso de Nutrição e docente do quadro permanente do Programa de Pós-Graduação em Saúde e Desenvolvimento na Região Centro-Oeste da Faculdade de Medicina (FAMEDqUFMS).E-mail: ritaaguimaraes@gmail.com, Orcid: http://orcid.org/0000-0003-2538-6707 
Resumo: O bombom é uma das formas mais populares de consumo de chocolate por causa de suas características sensoriais. A biomassa de banana-verde é um alimento com alegação de propriedades funcionais devido à presença de amido resistente, e a pitanga é um fruto explorado pela indústria por possuir $\beta$-caroteno, licopeno e vitaminas $A, C$ e E. Assim, nosso objetivo foi elaborar um bombom com acréscimo de biomassa de bananaverde e geleia de pitanga para testar sua vida útil e controle de qualidade. Analisou-se atividade de água, pH, umidade, acidez titulável, sólidos solúveis e testes microbiológicos. Os resultados foram positivos durante o tempo de estocagem estabelecido, garantindo vida útil do produto por trinta dias armazenado sob refrigeração. A análise microbiológica mostrou resultados satisfatórios, indicando que boas práticas de higiene e manipulação foram seguidas em todas as etapas de processamento e armazenamento, considerando a amostra apta para o consumo.

Palavras-chave: chocolate; análise microbiológica; análises físico-químicas; vida útil.

\begin{abstract}
Bonbon is one of the most popular forms of chocolate consumption because of its sensory characteristics. Green banana biomass is a food with a claim of functional properties due to the presence of resistant starch, and the pitanga is a fruit exploited by the industry for having $\beta$-carotene, lycopene and vitamins $A, C$ and $E$. Thus, our goal was to elaborate a bonbon with the addition of green banana biomass and pitanga jelly to test its life and quality control. Water activity, $\mathrm{pH}$, moisture, titratable acidity, soluble solids and microbiological tests were analyzed. The results were positive during the established storage time, guaranteeing product life for thirty days stored under refrigeration. The microbiological analysis showed satisfactory results indicating that good hygiene and handling practices were followed in all stages of processing and storage, considering the sample suitable for consumption.
\end{abstract}

Keywords: chocolate; microbiological analysis; physical-chemical analysis; lifespan.

Resumen: El bombón es una de las formas más populares de consumo de chocolate a causa de sus características sensoriales. La biomasa de plátano verde es un alimento con alegación de propiedades funcionales debido a la presencia de almidón resistente, y la pitanga es un fruto explotado por la industria por poseer $\beta$-caroteno, licopeno y vitaminas A, C y E. Así, nuestro objetivo fue elaborar un bombón con adición de biomasa de plátano verde y jalea de pitanga para probar su vida útil y control de calidad. Se analizó actividad de agua, $\mathrm{pH}$, humedad, acidez titulable, sólidos solubles y pruebas microbiológicas. Los resultados fueron positivos durante el tiempo de almacenamiento establecido, garantizando la vida útil del producto durante treinta días almacenados en refrigeración. El análisis microbiológico mostró resultados satisfactorios, indicando que las buenas prácticas de higiene y manipulación fueron seguidas en todas las etapas de procesamiento y almacenamiento, considerando la muestra apta para el consumo.

Palabras clave: chocolate; análisis microbiológico; análisis físico-químico; vida útil. 
Controle de qualidade de bombom funcional acrescido de biomassa de banana-verde e geleia de pitanga

\section{INTRODUÇÃO}

O bombom é uma das formas de se comercializar o chocolate e pode ser encontrado em diversos tipos, recheios e sabores, sendo distribuído mundialmente. A Resolução CNNPA n. 12, de 1978, que abrange o regulamento técnico para bombons e similares, define o bombom como um produto constituído por massa de chocolate ou por um núcleo formado de recheios diversos, elaborados com frutas, pedaços de frutas, sementes oleaginosas, açúcar, leite, manteiga, cacau, licores e outras substâncias alimentícias, podendo ser recobertos com uma camada de chocolate.

Para se obter um bombom com características adequadas, deve-se considerar a qualidade do chocolate, que é a principal matéria-prima do bombom e que, por sua vez, depende primordialmente da qualidade do cacau, de sua composição físico-química e de suas características sensoriais. Além disso, os recheios adicionados aos bombons devem ter processamento adequado durante a produção, pois podem ser excelentes meios de cultura para o desenvolvimento microbiano. Esses problemas podem ser minimizados por meio de fatores limitantes, como a reduzida atividade de água e baixo $\mathrm{pH}$.

Neste contexto, mesmo diante de uma produção de forma artesanal, é necessária a fiscalização de órgãos competentes, padronização de procedimentos de higiene e implementação de Boas Práticas de Fabricação como forma de prevenção para contaminações, tendo em vista que a ingestão de alimentos contaminados pode causar graves problemas para a saúde do consumidor e as chances de contaminação aumentam quando o processo é de forma manual.

A vida de útil de um alimento pode ser definida como o tempo em que o produto leva para se deteriorar até atingir um nível inaceitável de qualidade. A determinação da vida de prateleira deve levar em consideração aspectos de segurança alimentar, nutricionais e de aceitação pelo consumidor.

Além da preocupação com a qualidade sanitária dos produtos que consomem, os consumidores têm se preocupado cada vez mais com seus hábitos alimentares, tornando-se conscientes da importância de uma boa alimentação e sua relação com a qualidade de vida. 
Desta forma, conhecimentos sobre a relação entre alimentação e saúde, bem como os elevados custos da saúde pública e a busca permanente da indústria por inovações, vêm tendo um crescente avanço e, assim, gerado novos produtos, cujas funções pretendem ir além do conhecido papel nutricional dos alimentos. A comprovação das alegações de propriedades funcionais nos alimentos vem sendo identificada através de pesquisas de novos bioativos e o estabelecimento de bases científicas.

A oferta de alimentos funcionais aumenta a cada dia e, consequentemente, o interesse pelo estudo e desenvolvimento de novos produtos com tais características. Alimentos funcionais são aqueles que, ao serem consumidos, além de suas funções nutricionais, produzem também efeitos metabólicos e fisiológicos no organismo.

Entre esses alimentos, temos a biomassa de banana-verde, que é um produto que possui característica funcional por conter grande quantidade de amido resistente. $\mathrm{O}$ chamado amido resistente tem seu papel comparado ao de uma fibra dietética do tipo prebiótico, ou seja, possui fibras dietéticas solúveis e insolúveis e frutooligossacarídeos, cujas ações no organismo humano seriam, entre outras, a de melhora da função intestinal, retardamento no esvaziamento gástrico e diminuição dos índices de colesterol sanguíneo.

A biomassa da banana-verde pode ser empregada em diversos tipos de alimentos e até mesmo criar novas receitas. Uma das vantagens é não modificar as características sensoriais do alimento, atuar como um poderoso espessante, conferindo consistência, além de ser fonte de vitaminas, minerais, carboidratos e fibras solúveis e insolúveis.

Outro fruto que vem sendo estudado por suas características é o gênero Eugenia e, em particular, a espécie Eugenia uniflora L. (Myrtaceae). Popularmente conhecida no Brasil como pitangueira, é uma espécie arbórea nativa do Bioma Mata Atlântica que, recentemente, tem sido explorada pelas indústrias alimentícias, cosméticas e medicinais. A composição centesimal dos frutos da pitangueira consta de água (90\%), resíduo mineral $(0,28 \%)$, lipídios $(0,23 \%)$, proteínas $(0,76 \%)$, fibras $(2,10 \%)$, carboidratos totais (8,26\%) e valor calórico (30 kcal 100g-1), com teor de vitamina A de 990mcg 100g-1. Além de o fruto possuir compostos de interesse já identificados, como $\beta$-caroteno, vitamina $C$, vitamina $E$ e licopeno, sua utilização varia 
Controle de qualidade de bombom funcional acrescido de biomassa de banana-verde e

de preparo de polpa e suco, como também para a fabricação de sorvetes, refrescos, geleias, licores e vinhos.

Mediante o exposto, o objetivo deste trabalho foi elaborar um bombom com acréscimo de biomassa de banana-verde e geleia de pitanga com a finalidade de garantir segurança para o consumo, testando-se vida útil e controle de qualidade durante o tempo estabelecido para estocagem, através de análises físico-química e microbiológica.

\section{MATERIAL E MÉTODOS}

\subsection{Aquisição da matéria-prima}

O chocolate em barra classificado como meio amargo da marca Garoto $^{\circ}$ e o açúcar cristal foram adquiridos em supermercado da cidade de Campo Grande, Mato Grosso do Sul (MS). As bananas-verdes (Musa spp.), cultivar nanica in natura, utilizadas no preparo da biomassa, foram adquiridas comercialmente, estando estas em estágio de maturação completamente verde. As pitangas utilizadas para a elaboração da geleia foram coletadas no período de agosto a dezembro de 2016. Após coleta, foi realizada a seleção das frutas, sendo posteriormente higienizadas e, em seguida, armazenadas em congelador a-18 ${ }^{\circ} \mathrm{C}$ até o momento de preparo da geleia.

\section{Preparo da biomassa de banana-verde}

Todas as etapas de preparação da biomassa de banana-verde estão descritas na Figura 1. 
Figura 1 - Fluxograma do processamento da biomassa de banana verde

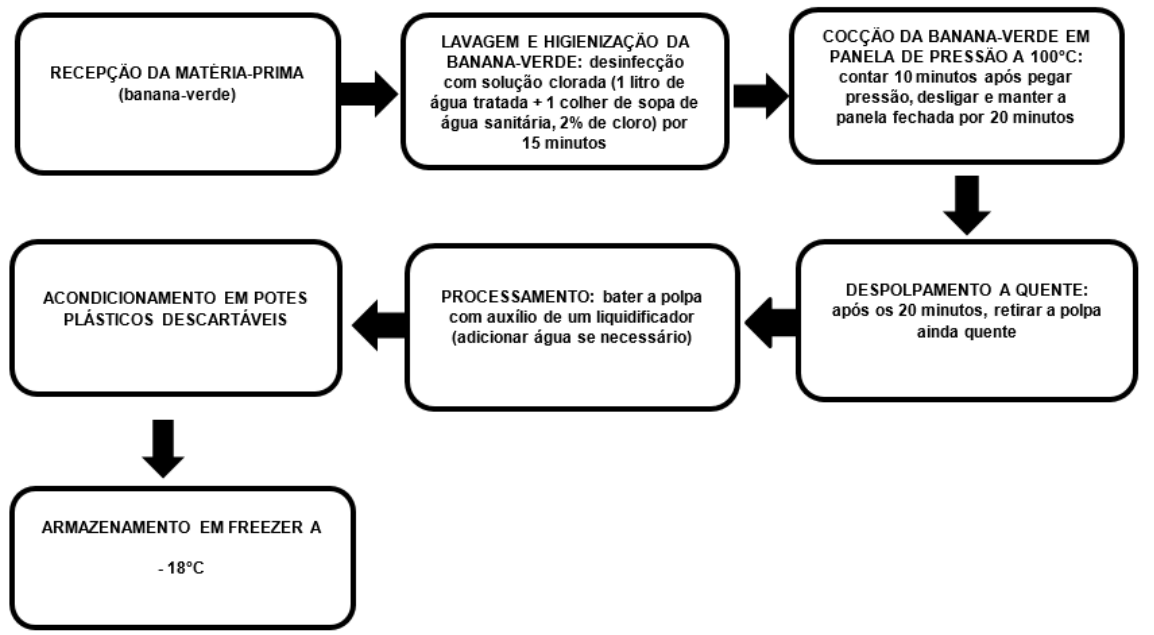

Fonte: Autoria própria.

\section{Preparo da geleia de pitanga}

Todas as etapas de preparação da geleia de pitanga estão descritas na Figura 2.

Figura 2 - Fluxograma do processamento da geleia de pitanga

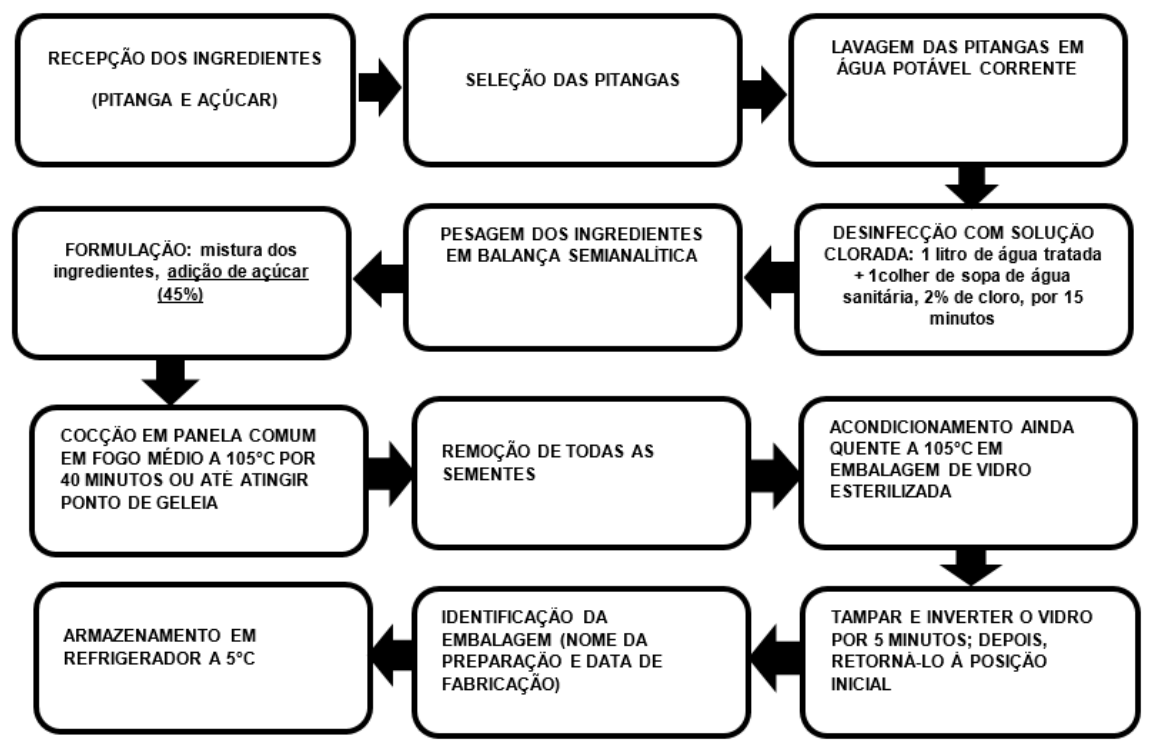

Fonte: Autoria própria. 
Controle de qualidade de bombom funcional acrescido de biomassa de banana-verde e geleia de pitanga

\section{Preparo do bombom}

O preparo do bombom foi realizado de forma artesanal, em que primeiramente pesou-se o chocolate utilizando balança semianalítica da marca Kitchen Scale ${ }^{\circledast}$. A barra de chocolate foi picada em pequenas partes, separando $1 / 4$ do total de chocolate utilizado. Em seguida, levou-se para derretimento em forno micro-ondas convencional Brastemp ', Brasil, em potência média, até total derretimento, chegando a uma temperatura de $45^{\circ} \mathrm{C}$ ao final.

Depois, realizou-se a temperagem pelo método de adição, o qual consiste em misturar ao chocolate derretido $1 / 4$ do total do chocolate picado anteriormente, deixando o chocolate pré-cristalizado a $29^{\circ} \mathrm{C}$, sendo esta a temperatura ideal para moldagem do bombom. Um termômetro digital da marca Incoterm foi utilizado para conferir todas as temperaturas durante o preparo. Ainda, foram pesados $100 \mathrm{~g}$ do chocolate derretido para preparo do ganache, em que foram adicionados $85 \mathrm{~g}$ (46\%) de biomassa de banana-verde com o chocolate, obtendo, assim, um dos recheios do bombom. Em seguida, preencheram-se as cavidades de uma forma plástica tipo acetato (BWB modelo 40 bombons 25g) com o chocolate derretido, e esta foi imediatamente colocada em refrigerador a $5^{\circ} \mathrm{C}$ durante 15 minutos. Após esse período, retirou-se a forma e preencheram-se as cavidades com os recheios, com o auxílio de saco de confeiteiro, colocando geleia de pitanga e ganache de biomassa de banana-verde. Para finalização do bombom, aplicou-se uma fina camada de chocolate sobre a superfície da forma, seguindo novamente à refrigeração a $5^{\circ} \mathrm{C}$ por 10 minutos. Na última etapa, procedeu-se à desmoldagem do bombom por inversão da forma. As amostras foram armazenadas sob refrigeração em temperatura de $5^{\circ} \mathrm{C}$ até o momento da análise.

\subsection{Análises físico-químicas}

As análises físico-químicas foram realizadas em laboratório de físico- química da Unidade de Tecnologia de Alimentos e Saúde Pública da UFMS (UTASP). Estabeleceram-se 30 dias como período de armazenamento, sob refrigeração a $5^{\circ} \mathrm{C}$, em que a amostra foi avaliada nos tempos: 1, 8, 15 e 22 dias. As determinações a seguir foram realizadas em triplicata, utilizando as seguintes metodologias: 


\section{Atividade de água (Aa):}

A atividade de água da amostra foi determinada através de aparelho medidor modelo Aw43. A amostra foi macerada com o auxílio de gral e pistilo, sendo colocados aproximadamente $5 \mathrm{~g}$ em frasco de plástico específico do aparelho, e então submetida à leitura após $1 \mathrm{~h}$.

\section{Sólidos solúveis ( $\left.{ }^{\circ} \mathrm{Brix}\right)$ :}

A determinação de sólidos solúveis da amostra foi realizada em refratômetro modelo HI 96801, através do índice de refração, seguindo a metodologia do Instituto Adolfo Lutz (BRASIL, 2005), sendo os resultados apresentados em ${ }^{\circ}$ Brix.

\section{Análise de pH:}

Primeiramente, pesaram-se $5 \mathrm{~g}$ da amostra previamente macerada e diluída em 20ml de água destilada; em seguida, determinou-se o $\mathrm{pH}$ em pHmetro de bancada (HANNA pH 21 pH/mV máster). O pH foi medido por imersão direta de eletrodo na amostra diluída, conforme metodologia descrita pelas Normas Analíticas do Instituto Adolfo Lutz (BRASIL, 2005).

\section{Acidez:}

A acidez foi determinada pelo método de titulação utilizando solução de $\mathrm{Na} \mathrm{OH}, 0,1 \mathrm{~N}$ e solução fenolftaleína, pelo método potenciométrico até $\mathrm{pH}$ 8,2 . Os resultados de acidez das amostras são expressos em solução molar por cento $\mathrm{v} / \mathrm{m}$, conforme metodologia descrita pelas Normas Analíticas do Instituto Adolfo Lutz (BRASIL, 2005).

\section{Umidade:}

A análise da umidade foi realizada em estufa a $105^{\circ} \mathrm{C}$ até peso constante. Foram pesados cerca de 4,0g de amostra em cadinhos previamente secos e tarados. A secagem foi realizada de acordo com as normas analíticas do Instituto Adolfo Lutz (BRASIL, 2005). Os resultados foram representados em g.100 g- ${ }^{1}$. 
Controle de qualidade de bombom funcional acrescido de biomassa de banana-verde e geleia de pitanga

\subsection{Análise microbiológica}

A amostra foi encaminhada para o laboratório de microbiologia de alimentos aproximadamente $72 \mathrm{~h}$ após a fabricação, sendo analisada durante quatro semanas consecutivas, com repetição em triplicata. As análises microbiológicas realizadas foram para Salmonella sp e Coliformes a $45^{\circ} \mathrm{C}$, de acordo com a Resolução-RDC no 12, de 2 de janeiro de 2001, da Agência Nacional de Vigilância Sanitária (Anvisa) do Ministério da Saúde (MS) (BRASIL, 2001), para chocolate e produtos similares em barra ou na forma de bombom, com adição ou não de outros ingredientes secos, classificados em categoria 5. A metodologia foi utilizada conforme a American Public Health Association, descrita no Compendium of Methods for the Microbiological Examination of Foods (VANDERZANT; SPLITTSTOESSER, 1992).

\subsection{Análise estatística}

Os resultados apresentados neste estudo correspondem à média de três repetições \pm desvio padrão. Foram considerados estatisticamente diferentes os resultados que apresentaram probabilidade de ocorrência da hipótese de nulidade menor que 5\% $(p<0,05)$, aplicando-se ANOVA, seguido de comparações múltiplas pelo teste de Tukey.

\section{RESULTADOS E DISCUSSÃO}

\subsection{Análises físico-químicas}

Na Tabela 1 estão descritos todos os resultados obtidos na análise físico-química do bombom funcional de biomassa de banana-verde com geleia de pitanga, durante todo o tempo de estocagem. 
Tabela 1 - Caracterização do bombom de biomassa de banana-verde com geleia de pitanga

\begin{tabular}{|c|c|c|c|c|}
\hline Parâmetros & 1a Semana & 2a Semana & 3a Semana & 4a Semana \\
\hline $\mathrm{pH}$ & $4,23 \pm 0,02^{a}$ & $4,81 \pm 0,02^{\mathrm{a}}$ & $4,81 \pm 0,03^{\mathrm{a}}$ & $4,67 \pm 0,01^{a}$ \\
\hline $\mathrm{Aa}$ & $0,836 \pm 0,04^{a}$ & $0,815 \pm 0,03^{a}$ & $0,842 \pm 0,01^{a}$ & $0,818 \pm 0,05^{a}$ \\
\hline $\begin{array}{c}\text { Sólidos solúveis } \\
\text { ('Brix) }\end{array}$ & $21,46 \pm 0,03^{\mathrm{a}}$ & $24,46 \pm 0,03^{a}$ & $26,9 \pm 0,02^{b}$ & $26,66 \pm 0,06^{b}$ \\
\hline 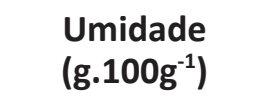 & $20,10 \pm 0,05^{a}$ & $19,66 \pm 0,04^{a}$ & $17,38 \pm 0,02^{b}$ & $17,23 \pm 0,02^{b}$ \\
\hline $\begin{array}{l}\text { Acidez titulável } \\
\text { (\%) }\end{array}$ & $12,55 \pm 0,01^{a}$ & $9,56 \pm 0,03^{b}$ & $9,27 \pm 0,01^{b}$ & $8,52 \pm 0,04^{b}$ \\
\hline
\end{tabular}

${ }^{1}$ Dados apresentados como média \pm desvio-padrão. Letras iguais na mesma linha não diferem entre si $(p>0,05)$.

Fonte: Autoria própria.

De acordo com os resultados obtidos, não houve diferença significativa $(p>0,05)$ para o parâmetro de $\mathrm{pH}$ analisado durante as semanas em que a amostra foi estudada; considerou-se a amostra analisada com $\mathrm{pH}$ pouco ácido. Quanto ao $\mathrm{pH}$, os alimentos são classificados em: muito ácidos ( $\mathrm{pH}<$ 4,0); ácidos (4,0<pH<4,5) e pouco ácidos ( $\mathrm{pH}>4,5)$ (AZEREDO et al., 2012). $\mathrm{O} \mathrm{pH}$ verificado na amostra foi similar ao valor encontrado por Medeiros et al. (2012) ao avaliarem trufas de caju feitas artesanalmente, com pH igual a 4,65, obtendo ao final do armazenamento (30 dias) resultados satisfatórios para a amostra analisada. Por outro lado, valores superiores foram verificados quando comparados com resultados reportados por Reolon et al. (2012) ao analisarem diferentes amostras de chocolate meio amargo comercializado no município de Campinas (SP), encontrando pH 6,1 $\pm 0,4$.

Valores superiores também foram encontrados no estudo de Richter e Lannes (2007), em que avaliaram bombom acrescido de ingredientes diet/ light e realizaram avaliação química e sensorial, encontrando resultados para $\mathrm{pH}(6,58 \pm 0,005)$ na formulação especial (ingredientes diet/light), comercial $(6,47 \pm 0,002)$ e controle $(6,73 \pm 0,005)$. Durante caracterização de chocolate branco com adição de erva-mate, Battiston et al. (2016) apresentaram valores para $\mathrm{pH}$ superiores quando comparado com resultados do presente estudo, encontrando $\mathrm{pH}(6,60 \pm 0,03)$ para formulação padrão 
Controle de qualidade de bombom funcional acrescido de biomassa de banana-verde e geleia de pitanga

F0- sem adição de extrato de erva-mate; $(6,61 \pm 0,00)$ F1- $1 \%$ e $(6,52 \pm 0,02)$ $3 \%$. O valor encontrado para $\mathrm{pH}$ pode ser explicado devido ao acréscimo de frutas no recheio do bombom do presente estudo. A análise de $\mathrm{pH}$ de um alimento é muito importante para determinação de vida útil, pois a maior parte dos microrganismos crescem em valores de $\mathrm{pH}$ ao redor de 7,0, enquanto poucos crescem em valores abaixo de 4,0.

Um dos fatores mais importantes para sobrevivência dos microrganismos é a disponibilidade de água, medida pela atividade de água ( $\mathrm{Aa}$ ). Os resultados da análise de Aa durante o tempo de estocagem não evidenciaram diferença significativa para os resultados no decorrer do tempo, sugerindo que o produto se mantém estável por este período. Este parâmetro é muito importante na análise para verificar a deterioração de um alimento. Com base nos resultados apresentados no estudo, podemos dizer que a amostra apresenta Aa intermediária, com valor médio de 0,828 durante o tempo de estocagem. De acordo com a Aa, os alimentos podem ser classificados em alto $(>0,85)$, intermediário $(0,60>\mathrm{Aa}<0,85)$ e baixo $(<0,60)$ (AZEREDO et al., 2012; ALMEIDA; FARIA; SILVA, 2012; SILVA, 2016).

Com relação aos valores encontrados para atividade de água (Aa), são similares aos obtidos em estudos de conservação de 90 dias de bombons com recheio à base de açúcar e fruta, nos quais se registraram valores próximos de Aa: 0,74- 0,76, sendo encontrada, no geral, uma ligeira diminuição nos valores durante o tempo avaliado, mas isso não influenciou as características dos produtos (MIQUELIM et al., 2011).

Os valores médios encontrados para atividade de água no presente estudo são superiores quando comparados no estudo de Reolon et al. (2012), que obtiveram resultado menor para esse parâmetro ao analisarem diferentes amostras de chocolate meio amargo (Aa: 0,42 $\pm 0,07)$.

Valores inferiores aos apresentados no estudo também foram reportados por Battiston et al. (2016) na avaliação de chocolate branco adicionado de diferentes concentrações de extrato de erva-mate, em que se obteve F0: 0,34 \pm 0,01 (sem adição de erva-mate), F1: 0,36 \pm 0,03 (com $1 \%$ de adição de erva-mate) e F2: 0,38 \pm 0,02 (com 3\% de adição de erva-mate), indicando que a adição do extrato não interferiu significativamente nos resultados para atividade de água e que os chocolates desenvolvidos 
apresentam estabilidade química e física, desde que armazenados em condições adequadas de umidade e temperatura. Ao compararmos os valores para atividade de água obtido na amostra do presente estudo com outros dados disponíveis na literatura, verificamos que a atividade de água aumenta devido à presença de frutas na composição da amostra.

Com relação aos valores encontrados para umidade, observou-se redução significativa $(p<0,05)$ a partir da terceira semana. Podemos observar que os valores para este parâmetro decresceram durante o período de armazenamento.

Valores superiores foram encontrados por Oliveira et al. (2015) na elaboração de chocolates com adição de inulina, obtendo-se valores para teor de umidade com 28,57\% para formulação padrão e 29,58\% para formulação com $5 \%$ de inulina.

De acordo com a Resolução CNNPA no 12, de 1978 (ANVISA, 1978), que fixa padrões de identidade e qualidade para chocolates, são recomendados para umidade valores de $20 \%$, estando os valores encontrados no presente estudo dentro desta recomendação.

Os resultados observados para sólidos solúveis mostraram diferença significativa $(p<0,05)$ a partir da terceira semana, apresentando valores superiores na terceira e na quarta semana, quando comparado com a primeira e a segunda. Para as análises de sólidos solúveis, não foram encontrados na literatura valores semelhantes ao produto elaborado neste estudo.

Miquelim et al. (2011) reportaram em seu estudo a estabilidade de bases de frutas na formulação de bombons para determinar vida de prateleira durante 90 dias, com valores superiores a ${ }^{\circ}$ Brix 65\% nas amostras analisadas, indicando que o uso de bases de frutas resultou em produto de baixo custo e maior vida útil em temperatura ambiente. Não existem valores específicos determinados para este parâmetro na legislação, porém podemos justificar o baixo valor apresentado no presente estudo pela adição da biomassa, em que, para seu processo de elaboração, a fruta passa por processo de cozimento.

Quanto aos valores analisados para a acidez titulável no presente estudo, o resultado da primeira semana diferiu significativamente das semanas seguintes em que a amostra foi avaliada. A primeira semana mostrou 
Controle de qualidade de bombom funcional acrescido de biomassa de banana-verde e geleia de pitanga

resultado maiores $(12,55 \% \pm 0,01)$ quando comparado com a segunda $(9,56 \% \pm 0,03)$, terceira $(9,27 \% \pm 0,01)$ e quarta semana $(8,52 \% \pm 0,04)$.

Freitas et al. (2017) apresentaram valores de acidez titulável para farinha de banana-verde (Musa sp.) prata $(7,00 \mathrm{p} / \mathrm{v})$ e nanica $(13,50 \mathrm{p} / \mathrm{v})$ ao caracterizarem essas farinhas para elaboração de pão de mel, estando estes acima do máximo permitido pela legislação para diversos outros tipos de farinhas. Tais fatos são explicados pela extração dos ácidos orgânicos muito presentes na matriz vegetal, sobretudo de frutas e hortaliças, quando submetidos ao tratamento hidrotérmico.

\subsection{Análise microbiológica}

O controle microbiológico em alimentos é realizado, principalmente, através da pesquisa de microrganismos indicadores que, quando presentes, podem fornecer informações sobre as condições sanitárias da produção, do processamento ou armazenamento, estimativa de vida de prateleira do produto, assim como a possível presença de patógenos. Vários fatores afetam a capacidade de sobrevivência ou o crescimento de microrganismos presentes num alimento. Entre esses fatores, existem os que se relacionam com as características do próprio alimento (fatores intrínsecos) e os associados ao ambiente (fatores extrínsecos) (AZEREDO et al., 2012).

De acordo com a Resolução-RDC n. 12, de 2 de janeiro de 2001 (Anvisa), para chocolate e produtos similares em barra ou na forma de bombom, com acréscimo ou não de outros ingredientes secos, devem ser analisados níveis de Coliformes a $45^{\circ} \mathrm{C}$ e Salmonella sp. Desse modo, os níveis

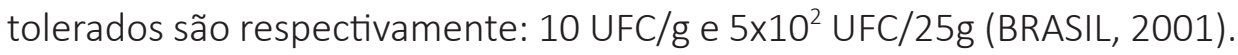

Amostras dos bombons em diferentes tempos de armazenamento foram analisadas e todas foram consideradas aptas para o consumo, estando abaixo ou igual ao estabelecido para o consumo. Não foi encontrada a presença de bolores e leveduras. Na Tabela 2 estão descritos os resultados da análise microbiológica da amostra. 
Tabela 2 - Análise Microbiológica em bombom de biomassa de bananaverde com geleia de pitanga

\begin{tabular}{cccccc}
\hline $\begin{array}{c}\text { Análise } \\
\text { executada }\end{array}$ & 1a Semana & 2a Semana & 3a Semana & 4a Semana & $\begin{array}{c}\text { Tolerância } \\
\text { p/ amostra } \\
\text { RDC } \mathbf{n} \mathbf{1 2}\end{array}$ \\
\hline $\begin{array}{c}\text { Coliformes } \\
\mathbf{4 5} \mathbf{C}\end{array}$ & $<3 \mathrm{NMP} / \mathrm{g}$ & $<3 \mathrm{NMP} / \mathrm{g}$ & $<3 \mathrm{NMP} / \mathrm{g}$ & $<3 \mathrm{NMP} / \mathrm{g}$ & 10 \\
$\begin{array}{c}\text { Salmonella sp } \\
\mathbf{2 5} \mathbf{g}\end{array}$ & Aus $/ 25 \mathrm{~g}$ & Aus $/ 25 \mathrm{~g}$ & $\mathrm{Aus} / 25 \mathrm{~g}$ & Aus $/ 25 \mathrm{~g}$ & Aus \\
\hline
\end{tabular}

$\mathrm{NMP}$ = número mais provável; Aus = Ausente .

Fonte: Autoria própria.

Os dados reportados pelo presente trabalho corroboram com estudo de Lubas et al., (2016) em que é analisada a qualidade microbiológica de barras de chocolate amargo e meio amargo adicionadas de castanha-de-baru (Dipteryx alata Vog.), nas proporções 15\%, 25\% e 35\%, produzidas artesanalmente, e em que foram obtidos resultados satisfatórios, estando todas as amostras aptas para o consumo e apresentando resultados abaixo ou iguais aos estabelecidos pela legislação; além disso, não foi detectada a presença de bolores e leveduras.

Em um outro estudo realizado por Medeiros et al. (2012), em que foram avaliadas trufas de caju, encontraram baixa contagem para bolores e leveduras $(<1 \times 10 \mathrm{UFC} / \mathrm{ml})$, com o produto mantendo-se inalterado ao longo de 30 dias de armazenamento sob refrigeração $\left(5^{\circ} \mathrm{C}\right)$. Também, ausência de coliformes $45^{\circ} \mathrm{C}$ (fecais) e coliformes $35^{\circ} \mathrm{C}$ (totais), indicando que as condições higiênico-sanitárias adotadas durante o processamento das trufas foram satisfatórias.

Franzen et al. (2015) verificaram a qualidade microbiológica de bombom de frutas com adição de proteína vegetal e chia (Salvia hispânica L.), encontrando valores dentro do limite estabelecido pela Resolução RDC 12, de 2 de janeiro de 2001, o que demonstra que os bombons não ofereciam riscos à saúde dos consumidores. Ao serem analisadas, amostras de barras de chocolate amargo e meio amargo adicionadas de chia, nas maiores concentrações, de 35\% mostraram-se aptas para o consumo., apresentando valores abaixo ou igual aos estabelecidos pela legislação vigente para 
Controle de qualidade de bombom funcional acrescido de biomassa de banana-verde e geleia de pitanga

Coliformes a $45^{\circ} \mathrm{C}$ e Salmonella sp. (10 UFC/g e 5×10² UFC/25g) para análise microbiológica de chocolates e similares em barra ou na forma de bombom, além de ausência de bolores e leveduras (PAIVA et al., 2017).

Por outro lado, resultados diferentes foram verificados em uma análise em que se avaliaram condições higiênico-sanitárias da fabricação de bombons de chocolate com recheios de frutas de alguns estabelecimentos da cidade de Belém (PA). Neste estudo em questão, não houve presença de Salmonella sp. e Estafilococos coagulase-positiva nas amostras de bombons analisadas. Entretanto, no total das 57 amostras analisadas, um percentual de $12,3 \%$ apresentou valores fora do estabelecido pela legislação vigente (10NMP/g) para coliformes $45^{\circ} \mathrm{C}$ (fecais), sendo esse percentual de produção caseira. O estudo ainda identificou a presença de bactérias aeróbias mesófilas e de bolores e leveduras, tanto nos bombons de produção caseira quanto industrial, indicando higienização deficiente durante a elaboração dos produtos (SOUSA et al., 2010). A análise microbiológica de um alimento é de extrema importância para garantir que o alimento esteja em boas condições para o consumo humano.

Assim, é de extrema importância o controle tanto da matéria-prima quanto do processamento durante a fabricação de chocolates, sendo esses fatores essenciais na prevenção de patógenos em chocolate (REOLON et al., 2012).

\section{CONCLUSÃO}

Todos os alimentos sofrem graus variados de deterioração. As alterações responsáveis por perda de qualidade são de vários tipos, incluindo reações químicas e alterações microbiológicas e físicas durante a estocagem. $\mathrm{O}$ desenvolvimento do bombom acrescido de biomassa de banana-verde e geleia de pitanga mostrou resultados positivos através das análises. A amostra não apresentou nenhum tipo de alteração durante os 30 dias determinados para a estocagem e análises, garantindo, assim, grau de segurança para o consumo durante este período, estando armazenada sob refrigeração, o que assegurou, desta forma, vida útil e controle de qualidade do produto. 
Outro ponto positivo mostra que, mesmo diante de uma produção de forma artesanal, as análises microbiológicas do bombom indicaram que as boas práticas de higiene e manipulação foram seguidas em todas as etapas de processamento e armazenamento da amostra, uma vez que não foram indicados microrganismos patogênicos nas amostras analisadas, nem mesmo presença de bolores e leveduras.

De acordo com os resultados obtidos neste estudo, a adição de biomassa de banana-verde e geleia de pitanga manteve a caracterização de um bombom recheado, além de contribuir para agregar valores a esses frutos. Vale ressaltar que, além deste, outros estudos devem ser realizados para avaliação sensorial e composição centesimal do produto, já que essa análise não foi aplicada neste estudo.

\section{REFERÊNCIAS}

ALMEIDA, D. J.; FARIA, M. S.; SILVA, P. R. Biologia experimental em pitangueira: uma revisão de cinco décadas de publicações científicas. Revista Ambiência, Guarapuava, PR, v. 8, n. 1, p. 177-93, jan./abr. 2012.

AGÊNCIA NACIONAL DE VIGILÂNCIA SANITÁRIA (ANVISA). Resolução CNNPA n. 12, de 1978. "Comissão Nacional de Normas e Padrões para Alimentos". Diário Oficial da União, Brasília, DF, Poder executivo, 24 de julho de 1978. Área de atuação: alimentos. Regulamento técnico por assunto. Bombons e similares.

AZeredo, H. M. C.; PINTO, G. A.; BRITO, E, S.; AZERedo, R. M. C. Alterações microbiológicas em alimentos durante a estocagem. In: AZEREDO, H. M. C. (Ed. Téc.). Fundamentos de estabilidade de alimentos. 2. ed. Brasília, DF: Embrapa, 2012.

BATTISTON, C. S. Z.; DALLA ROSA, C.; BARROS, N. P. R.; MIGNONI, M. L. Caracterização físico-química e atividade antioxidante de chocolate branco com extrato de ervamate. Revista virtual de Química, Niterói, RJ, v. 8, n. 6, p. 1878-88, nov./dez. 2016.

BRASIL. Ministério da Saúde. Agência Nacional de Vigilância sanitária. Métodos físico-químicos para análise de alimentos. 4. ed. Brasília: Ministério da Saúde, 2005.

BRASIL. Ministério da Saúde. Resolução - RDC n. 12, de 2 de janeiro de 2001. Aprova o regulamento técnico sobre padrões microbiológicos para alimentos. Brasília, 2001. 
Controle de qualidade de bombom funcional acrescido de biomassa de banana-verde e geleia de pitanga

FRANZEN, C. F. Bombom de frutas com adição de proteína vegetal e chia. Tecnologias para Competitividade Industrial, Florianópolis, v. 8 n. 1, p. 125-39, jul. 2015.

FREITAS, M. C. J.; DA SILVEIRA, G. E.; VERAS, S. L S.; SANTOS, G. F. F. Pães de mel elaborados com farinha de diferentes variedades de banana verde. DEMETRIA: Alimentação, Nutrição e Saúde, Rio de Janeiro, v. 12, n. 2, p. 465-82, 2017.

LUBAS, C. C.S.; CANDIDO, C. J.; SOUZA, S. V. S.; GUIMARÃES, R. C. A. Qualidade nutricional de barras de chocolate adicionadas de castanha de baru. Multitemas, Campo Grande, MS, v. 21, n. 49, p. 181-92, jan./jun. 2016

MEDEIROS, M. J. M.; SILVA, J. F.; FAUSTINO, M. V. S.; SANTOS, M. F. G.; ROCHA, L. C. S.; CARVALHO, L. C. Aceitação sensorial e qualidade microbiológica de trufas de caju obtidas artesanalmente. HOLOS, Natal, RN, v. 2, n. 28, p. 77-86, fev. 2012.

MIQUELIM, J. N.; ALCANTARA, M. R.; LANNES, S. C. S. Estabilidade de bases de frutas e recheios para chocolates. Ciência e Tecnologia de Alimentos, Campinas, SP, v. 31, n. 1, p. 270-6, jan./mar. 2011.

OLIVEIRA, M. C.; SANTOS, E. F.; CANDIDO, C. J.; RODRIGUES, B. M.; HOKAMA, L. M.; NOVELLO, D. Elaboração de chocolate com adição de inulina: análise físico-química e sensorial. Revista Uniabeu, Belford Roxo, RJ, v. 8, n. 19, p. 321-36, maio/ago. 2015.

PAIVA, C. F.; HOKAMA, L. M.; CANDIDO, C. J.; GUIMARÃES, R. C. A. Elaboração de barras de chocolate funcionais enriquecidas com chia. Multitemas, Campo Grande, MS, v. 22, n. 52, p. 185-99, jul./dez. 2017.

REOLON, E. M.; SANTOS, A. R B.; MOREIRA, V. E.; DO NASCIMENTO, M. S. Pesquisa de enterobacterias em chocolates. Revista do Instituto Adolfo Lutz, São Paulo, v. 71, n. 1, p. 40-3, jan. 2012.

RICHTER, M.; LANNES, S. C. D. S. Bombom para dietas especiais: avaliação química sensorial. Ciência e Tecnologia de Alimentos, Campinas, SP, v. 27, n. 1, p. 193-200, jan./mar. 2007.

SILVA, M. M. et al. A caracterização da bananicultura em São Bento do Sapucai: saberes gastronômicos na Serra da Mantiqueira. Ágora, Santa Cruz do Sul, RS, v. 18, n. 01, p. 108-18, jan./jun. 2016

SOUSA, L. C. et al. Avaliação microbiológica, físico-química e das condições de fabricação de bombom de chocolate com recheio de frutas. Revista Alimentos e Nutrição, Araraquara, SP, v. 21, n. 2, p. 305-10, jun. 2010. 
VANDERZANT, C.; SPLITTSTOESSER, F. Compendium of methods for the microbiological examination of foods. 3. ed. Washington, DC: APHA, 1992. 